artificial chordae implantation in patients with mitral valve prolapse. J Heart Valve Dis 1997; 6:594-8.

6. McCarthy JF, Neligan MC, Wood AE. Ten years' experience of an aggressive reparative approach to congenital mitral valve anomalies. Eur J Cardiothorac Surg. 1996;10:534-9.

7. Oda S, Nakano T, Tatewaki H, Hinokiyama K, Machida D, Kado H. A17-year experience with mitral valve repair with artificial chordae in infantsand children. Eur ] Cardiothorac Surg 2013;44: e40-5.

8. Jolanda Kluin, Vladimir Sojaka et al. Fifteen years' experience with the use of artificial chords for valve reconstruction in children. European Journal of Cardio-Thoracic Surgery, Volume 52, Issue 6, 2017, p1155-1160.

\title{
SỰ TĂNG TRƯỞNG CHIỀU RộNG CUNG RĂNG Ở CÁC GIAI ĐOẠN CỦA TRẺ EM MƯờNG TỪ 12 ĐẾN 14 TUỔI
}

\author{
Vũ Văn Xiêm ${ }^{1}$, Nguyễn Van $\mathrm{Ba}^{2}$, Đặng Triệu Hùng ${ }^{3}$, \\ Võ Trương Như Ngọc ${ }^{4}$, Trương Mạnh Dũng
}

\section{TÓM TẮT}

Mục tiêu: Đánh giá sự thay đổi kích thước cung răng của trẻ em người Mường Viêt Nam từ 12 đến 14 tuổi. Chất liệu và phương pháp: Nghiên cứu được thực hiện trên 678 Mẫu thach cao cung răng được lẩy từ 226 đối tượng (107 nam;; 119 nữ) là trẻ em Mường 12 tuổi trong 3 năm, mỗi năm 1 lần. Các đối tượng nàykhông có dị tật bẩm sinh, có đủ 28 răng vĩnh viễn, không bi mất kích thước răng, trẻ chưa điêuu tri chỉnh hình răng mặt hay phẫu thuật hàm mặt. Đo đạc kích thước cung răng trên mẫu hàm thach cao và xác đinh sự thay đối kích thước cung răng ở các giai đoạn khác nhau của các đối tượng nghiên cứu. Kết quả: Giai đoạn 12 đến 14 tuổi tất cả chiều rộng cung răng hàm trên của nam và của nữ đều tăng, sự thay đổi từ 0,23 $\mathrm{mm}$ đến $1,34 \mathrm{~mm}$, sự thay đổi này có ý nghĩa thống kê $(p<0,05)$. Chiều rộng các cung răng sau trên của nam (R66T tăng 0,67 mm, R77T tăng 1,34 mm) tăng nhiều hơn chiều rộng các cung răng sau trên của nữ (R66T tăng 0,42 mm, R77T cũng tăng 0,42 mm). RTT của nam (tăng $0,42 \mathrm{~mm}$ ) hàm trên tăng chậm hơn so với RTT của nữ (tăng $0,45 \mathrm{~mm}$ ). Chiêuu rộng giữa trên của nam (tăng $0,34 \mathrm{~mm}$ ) tăng mạnh hơn so với rộng giữa trên của nữ (tăng $0,23 \mathrm{~mm}$ ). Ở giai đoạn này chiều rộng cung răng hàm dưới của nam và nữ đều tăng, sự thay đổi từ $0,01 \mathrm{~mm}$ đến $0,77 \mathrm{~mm}$. sự thay đổi đều có ý nghĩa thống kê $(p<0,05)$. RTD và $R G D$ của nam (tăng 0,03 và $0,01 \mathrm{~mm}$ ) tăng chậm hơn so với ở nữ (tăng 0,11 và $0,08 \mathrm{~mm}$ ). Giống giai đoạn khác các chiều rộng cung răng sau dưới $\left(\mathrm{RSD}_{1}, \mathrm{RSD}_{2}\right)$ của nam đều tăng nhanh hơn so với của nữ. Kết luân: Nghiên cứu đã xác định được xu hướng cũng như tốc độ tăng trưởng của cung răng của trẻ em người Mường giai đoan 12 đến 14 tuổi.

Tư khóa: Cung răng, tăng trưởng, 12-14 tuổi.

\footnotetext{
${ }^{1}$ Bênh viên Đa khoa YHCT Hà Nôi

${ }^{2}$ Học viện Quân Y 103

${ }^{3}$ Viện Đào tạo Răng Hàm Mặt

Chịu trách nhiệm chính: Vũ Văn Xiêm

Email: vuvanxiem70@gmail.com

Ngày nhận bài: 30/4/2021

Ngày phản biên khoa học: 19/5/2021

Ngày duyệt bài: 12/6/2021
}

\section{SUMMARY \\ DENTAL ARCH DIMENSIONAL CHANGES OF MUONG VIETNAMESE CHILDREN FROM 12 TO 14 YEARS}

Objectives: To evaluate dental arch dimensional changes of Muong Vietnamese children. Material and methods: 678 dental casts were taken from 226 children of Muong ethnic group (107 males; 119 females) with parmanent dentition. Thesestudents were selected from secondary schools aged 12, according to the following criteria: Well-aligned upper and lower dental arches,parmanent dentition with 28 teeth, good facial symmetry and no previous orthodontic treatment. Dental arch dimensions were taken by one examiner using an electronic digital sliding caliper. The t-test was used to compare the dental arch dimensions ofthe subject groups.. Results: From 12 to 14 years of age, all maxillary arch widths of males and femalesincreased, the change ranged from $0.22 \mathrm{~mm}$ to $1.34 \mathrm{~mm}$. This change was statistically significant $(p<0,05)$. The widths of the upper posterior arches of males(U66W increased by $0.67 \mathrm{~mm}$, U77W increased by $1.34 \mathrm{~mm}$ ) increased more than that of females(U66W increased by $0.42 \mathrm{~mm}, \mathrm{U} 77 \mathrm{~W}$ also increased by $0.42 \mathrm{~mm}$ ). Besides, the upper intercanine withs (U33W) of males (which saw anincrease of $0.42 \mathrm{~mm}$ ) increased more slowly than that of thefemales (which increased by $0.45 \mathrm{~mm}$ ). The males' upper middle widths (U55W) (which increased by $0.34 \mathrm{~mm}$ ) was greater than that of thefemales upper middle widths (increased by $0.23 \mathrm{~mm}$ ). At this stage, the widths of the lower arches of both males and females increased, the change ranged from $0.01 \mathrm{~mm}$ to $0.77 \mathrm{~mm}$. This change was statistically significant $(p<0,05)$. the lower intercanine withs (L33W) and the lower inter-second premolar withs of males(increasedby 0.03 and $0.01 \mathrm{~mm}$ ) increased more slowly than that of the females (increased by 0.11 and $0.08 \mathrm{~mm}$ ). The lower posterior arch widths (L66W, L77W) of malesincreased more than that of females. Conclusions: The trend as well as the growth rate of the dental arches of Muong children between the ages of 12 and 14 has been determined.

Key words: Dental arch, Growth, 12-14 years old. 


\section{I. ĐĂT VẤN ĐỀ}

Tăng trưởng cung răng có ý nghĩa quan trọng vì nhờ nó chúng ta mới có kế hoạch điều trị chỉnh hình phù hợp. Để xác định sự bất thường của bộ răng người bác sỹ chỉnh nha cần có đủ kiến thức để phân biệt bất thường và bình thường trước khi bắt đầu liệu pháp điều trị ${ }^{1}$

Kích thước cung răng thay đổi một cách có hệ thống có những kích thước tăng, có những kích thước giảm nhưng cũng có những kích thước tăng hoặc giảm ở từng giai đoạn do đó nhiêu nghiên cứu trên thế giới đã khảo sát những thay đổi về kích thước của cung răng trong các giai đoạn tăng trưởng và phát triển khác nhau ${ }^{2}$

Trong giai đoạn khởi đâu của bộ răng vĩnh viễn những thay đổi xảy ra trong cung răng là kết quả của sự di chuyển răng và sự phát triển của xương nâng đỡ, bên cạnh yếu tố di truyền ${ }^{3}$

Thời kỳ tăng trưởng và phát triển bị ảnh hưởng bởi các yếu tố như yếu tố dân tộc, yếu tố môi trường, dinh dưỡng, yếu tố toàn thân nhưng hầu hết các tác giả đều khảng định rằng các đặc điểm cung răng có sự khác nhau giữa các dần tộc. Đặc điểm này được cân nhắc trong quá trình điều trị̆ . Một số nghiển cứu đã cố gắng xác định các đặc điểm của cung răng của riêng một nhóm dân tộc nhất định. Năm 2002 ở Việt nam Lê Đức Lánh đã nghiên cứu quá trình tăng trưởng cung răng vĩnh trẻ em người Kinh? ${ }^{7}$. Tuy nhiên đã có một số nghiên cứu tăng trưởng của trẻ em nhứng chưa có nghiên cứu nào trên người Mường. Mục đích của nghiên cứu này là đánh giá thay đổi kích thước cung răng ở bộ răng vĩnh viễn của trẻ em người Mường.

\section{CHẤT LIỆ, ĐỐI TƯợNG VÀ PHƯƠNG PHÁP NGHIẾN CỨU}

1. Chất liệu nghiên cứu: Gồm 678 mẫu hàm thạch cao cung răng được lấy dấu từ 226 đối tượng (Mỗi năm 1 lần)

2. Đối tượng nghiên cứu. Gồm 226 Trẻ em Mường 12 tuổi, được chọn từ 7trường phổ thông trung học cơ sở thuộc 7 xã dân tộc Mường, huyện Kim Bôi, tỉnh Hoà Bình.

Tiêu chuấn lựa chọn ở giai đoạn bắt đâu nghiên cứu. Đối tượng lựa chọn khổng có dị tật bẩm sinh. Không mắc các bệnh ảnh hưởng tới sự phát triển của cung răng. Chưa từng điều trị chỉnh nha. Có đủ 28 răng vĩnh viễn bình thường trên cung hàm. Các răng không bị sứt mẻ, sâu gây ảnh hưởng tới kích thước của cung răng và các điểm mốc đo.

Tiêu chuẩn loại trừ: Trẻ em còn tồn tại răng sữa, hoặc răng thừa, trong quá trình tham gia nghiên cứu trẻ bị chấn thương vùng hàm mặt hoặc phẫu thuật thẩm mỹ hoặcnắn chỉnh răng.

\section{Phương pháp nghiên cứu}

3.1. Thời gian nghiên cứu: Từ tháng 11 /2016 - 11 / 2020

3.2. Thiết kế nghiên cứu: Theo phương pháp mô tả theo dõi dọcgồm 226 trẻ em.Các trẻ em này được khám và lấy dấu cung răng 3 lần, mỗi năm một lần từ năm 12 tuổi đến năm 14 tuổi vào cùng một thời điểm trong mỗi năm.

\subsection{Các bước tiến hành}

Bước 1: Thăm khám sơ bộ sàng lọc, lập danh sách, lựa chọn đối tượng nghiên cứu.

Bước 2: Lây dấu, đổ mẫu.

Bước 3: Khám thu thập dữ liệu: Lãy dấu, đổ mẫuthach cao siêu cứng và mã hóa mẫu hàm. Đo các kích thước cung răng, Nhập và xử lý số liệu

3.4. Dụng cụ và vật liệu để thu thập dữ liệu. Thước trượt điện tử 2 đầu nhọn có độ chính xác đến $0,01 \mathrm{~mm}$. Gương khám trong miệng, gắp, thám trâm, thìa lấy dấu, chất lấy dấu, thạch cao, máy trộn chất lấy dấu, máy mài mẫu, phiếu phân tích trền mẫu,...

\subsection{Thu thập dữ liệu về cung răng trên} mấu hàm thạch cao. Các mốc đo kích thước rộng cung răng: Chúng tôi tham khảo sự lựa chọn mốc của Lê Đức Lánh7, Phạm Cao Phong ${ }^{8}$

Để xác định kích thước cung răng ở lứa tuổi 12-14, chúng tôi chọnvà đánh dấu các mốc đo như sau: Các điểm mốc được chọn là đỉnh múi răng nanh, đỉnh múi ngoài răng hàm nhỏ thứ hai, đỉnh múi gần ngoài răng cối lớn thứ nhất, các đỉnh múi xa ngoài răng cối lớn thứ hai. Từ các điểm mốc này tiến hành xác định các kích thước chiều rộng cung răng. (Hình.1)

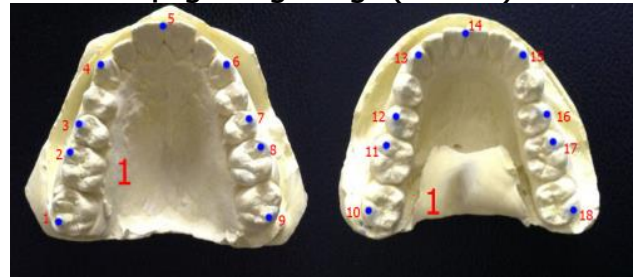

Hinh 1. Các mốc đo kích thước rông cung răng Các biến số thu thập (8 kích thước rộngcung răng, hình 2)

$>$ Chiều rộng cung răng trước trên (RTT) và dưới (RTD): Đ̇o khoảng cách giữa 2 đỉnh múi răng nanh hàm trên và khoảng cách giữa 2 đỉnh múi răng nanh hàm dưới.

$>$ Chiều rộng cung răng giữa trên (RGT) và dưới (RGD): Đo khoảng cách giữa 2 đỉnh múi ngoài răng hàm nhỏ thứ hai hàm trên và đo khoảng cách giữa 2 đỉnh múi ngoài răng hàm nhỏ thứ hai hàm dưới. 
$>$ Chiêu rộng cung răng sau trên 1 (RST 1 ), sau dưới $1\left(R^{2} D_{1}\right)$ : Đo khoảng cách giữa 2 đỉnh múi ngoài gần răng hàm lớn thứ nhất hàm trên và đo khoảng cách giữa 2 đỉnh múi ngoài gần răng hàm lớn thứ nhất hàm dưới.

$>$ Chiều rộng cung răng sau trên $2\left(\mathrm{RST}_{2}\right)$, sau dưới $2\left(\mathrm{RSD}_{2}\right)$ : Đo khoảng cách giữa 2 đỉnh múi xa ngoài răng hàm lớn thứ hai hàm trên và đo khoảng cách giữa 2 đỉnh múi xa ngoài răng hàm lớn thứ hai hàm dưới.

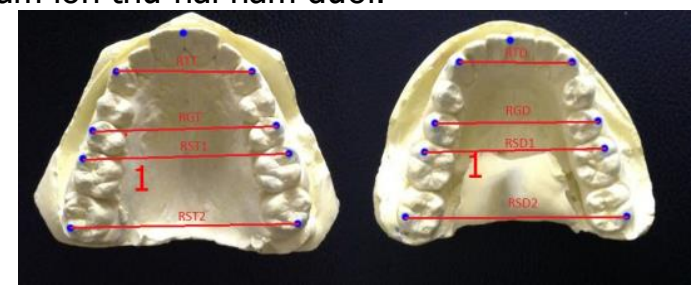

Hình 2. Các kích thước chiều rộng cung răng

\begin{tabular}{|c|c|}
\hline $\begin{array}{l}\text { RTT: Chiêu rộng } \\
\text { trước trên (R33T) }\end{array}$ & $\begin{array}{l}\text { RTD: Chiều rộng trước } \\
\text { dưới(R33D) }\end{array}$ \\
\hline $\begin{array}{l}\text { RGT: Chiêu rộng } \\
\text { giữa trên(R55T) }\end{array}$ & $\begin{array}{c}\text { RGD: Chiêu rộng trước } \\
\text { dưới(R55D) }\end{array}$ \\
\hline $\begin{array}{l}\text { RST1: Chiều rộng } \\
\text { sau trên1(R66T) }\end{array}$ & $\begin{array}{l}\mathrm{RSD}_{1} \text { : Chiêu rộng trước } \\
\text { dưới(R66D) }\end{array}$ \\
\hline $\begin{array}{l}\text { RST }_{2} \text { : Chiều rộng } \\
\text { sau trên2(R7TT) }\end{array}$ & $\begin{array}{c}\text { RSD }_{2} \text { : Chiều rộng trước } \\
\text { dưới(R77̄D) }\end{array}$ \\
\hline
\end{tabular}

3.6. Đạo đức nghiên cứu: Quá trình nghiên cứu được sự cho phép của hội đồng đạo đức trường Đại học Y Hà Nội.

\section{KẾT QUẢ NGHIÊN CỨU}

\section{1. Đăcc điểm chung của mẫu nghiên cứu}

Mẫu nghiên cứu gồm 226 (Lớn hơn so với tính toán theo công thức) đối tượng chia thành 2 nhóm: 107nam và 119 nũ̃.

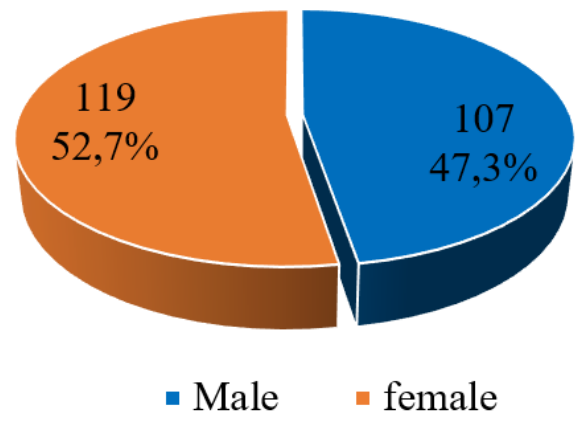

Biểu đồ 3.1. Phân bố đôi tượng nghiên cứu theo giới Nhận xét: - Đối tượng nam chiếm tî lệ 47,3\% (107đối tượng) và đối tượng nữ chiếm 52,7 \% (119đối tượng).

- Đối tương nam ít hơn đối tượng nữ, tuy nhiên sự khác biệt này không có ý nghĩa thống kê $(p>0,05)$.

2. Sự tăng trưởng chiêu rộng cung răng của trẻ em Mường ở các giai đoạn từ 12 đến 14 tuổi.

2.1. Sự tăng trưởng chiều rộng cung răng giai đoạn từ 12 đến 13 tuổi Bảng 3.1. Tăng trưởng chiều rộng cung răng giai đoạn 12-13 tuối

\begin{tabular}{|c|c|c|c|c|c|c|}
\hline $\begin{array}{l}\text { Đặc điếm nghiên } \\
\text { cứu (mm) }\end{array}$ & $\begin{array}{c}X \\
\text { năm } 12 \\
\end{array}$ & $\begin{array}{c}\sigma \\
\text { năm } 12\end{array}$ & $\begin{array}{c}X \\
\text { năm13 } \\
\end{array}$ & $\begin{array}{c}\sigma \\
\text { năm } 13\end{array}$ & $\begin{array}{c}\Delta \\
(12-13)\end{array}$ & $\begin{array}{c}\mathbf{p} \\
(12-13)\end{array}$ \\
\hline Nam: R33T & 36,21 & 1,81 & 36,51 & 1,76 & $-0,30$ & $0.0000 * * *$ \\
\hline R55T & 49,90 & 2,22 & 49,97 & 2,60 & $-0,07$ & $0.0000 * * *$ \\
\hline R66T & 54,73 & 2,21 & 55,03 & 2,62 & $-0,30$ & $0.0000 * * *$ \\
\hline R77 T & $59,06$. & 2,65 & 59,67 & 2,77 & $-0,62$ & $0.0010 * * *$ \\
\hline R33T & 35,07 & 1,80 & 35,35 & 1,78 & $-0,27$ & $0.0000 * * *$ \\
\hline R55T & 48,17 & 2,37 & 48,25 & 2,37 & $-0,07$ & $0.0000 * * *$ \\
\hline R66T & 53,00 & 2,23 & 53,23 & 2,35 & $-0,22$ & $0.0000 * * *$ \\
\hline R77T & 57,87 & 2,71 & 57,90 & 2,73 & $-0,03$ & $0.0010 * * *$ \\
\hline Nam: R33D & 27,82 & 1,69 & 27,57 & 2,14 & 0,25 & $-0.0016 * * *$ \\
\hline R55D & 41,78 & 2,32 & 41,59 & 2,55 & 0,18 & $0.0000 * * *$ \\
\hline R66D & 47,08 & 2,25 & 47,35 & 2,25 & $-0,27$ & $0.0000 * * *$ \\
\hline R77D & 54,56 & 2,81 & 54,77 & 2,80 & $-0,21$ & $0.0000 * * *$ \\
\hline R33D & 26,76 & 1,71 & 26,71 & 1,90 & 0,04 & $-0.0016 * * *$ \\
\hline R55D & 39,98 & 2,35 & 39,89 & 2,57 & 0,08 & $0.0000 * * *$ \\
\hline R66D & 45,53 & 2,21 & 45,65 & 2,29 & $-0,11$ & $0.0000 * * *$ \\
\hline R77D & 52,53 & 2,60 & 52,55 & 2,46 & $-0,02$ & $0.0000 * * *$ \\
\hline
\end{tabular}

Nhân xét: Các kích thước chiều rộng cung răng từ năm 12 tuối đến 13 tuối ở hàm trên, hàm dưới ở nam và nữ đều tăng. Sự thay đổi có ý nghĩa thống kê $(p<0,05)$. Riêng đối với kích thước chiều rộng trước dưới và giữa dưới ở hàm dưới của nam và nữ giảm có ý nghĩa thống kê $(p<0,05)$.

\subsection{Sự tăng trưởng chiêu rộng cung răng giai đoạntừ 13 đến 14 tuổi}

Bảng 3.2. Tăng trưởng chiều rộng cung răng giai đoạn 13-14 tuổi 
TẠP CHÍ Y HỌC VIẸT NAM TẠP 504 - THÁNG 7 - SÓ 1 - 2021

\begin{tabular}{|c|c|c|c|c|c|c|}
\hline $\begin{array}{l}\text { Đặc điếm nghiên } \\
\text { cứu (mm) }\end{array}$ & $\begin{array}{c}X \\
\text { năm } 13\end{array}$ & $\begin{array}{l}\sigma \\
\text { năm } 13\end{array}$ & $\begin{array}{c}X \\
\text { năm14 }\end{array}$ & $\begin{array}{c}\sigma \\
\text { năm } 14\end{array}$ & $\begin{array}{c}\Delta \\
(13-14)\end{array}$ & $\begin{array}{c}p \\
(13-14)\end{array}$ \\
\hline Nam: R33T & 36,50 & 1,76 & 36,62 & 1,81 & $-0,12$ & $0.0000 * * *$ \\
\hline R55T & 49,97 & 2,60 & 50,24 & 2,65 & $-0,27$ & $0.0000 * * *$ \\
\hline R66T & 55,03 & 2,62 & 55,40 & 2,64 & $-0,37$ & $0.0000 * * *$ \\
\hline R77 T & 59,67 & 2,77 & 60,40 & 2,81 & $-0,72$ & $0.0000 * * *$ \\
\hline R33T & 35,35 & 1,78 & 35,52 & 1,81 & $-0,17$ & $0.0000 * * *$ \\
\hline R55T & 48,25 & 2,37 & 48,40 & 2,40 & $-0,15$ & $0.0000 * * *$ \\
\hline R66T & 53,23 & 2,35 & 53,42 & 2,45 & $-0,19$ & $0.0000 * * *$ \\
\hline R77T & 57,90 & 2,73 & 58,29 & 2,92 & $-0,39$ & $0.0000 * * *$ \\
\hline Nam: R33D & 27,58 & 2,14 & 27,85 & 1,98 & $-0,27$ & $0.0013^{* *}$ \\
\hline R55D & 41,59 & 2,55 & 41,79 & 2,52 & $-0,20$ & $0.0000 * * *$ \\
\hline R66D & 47,35 & 2,58 & 47,74 & 2,52 & $-0,39$ & $0.0000 * * *$ \\
\hline R77D & 54,77 & 2,80 & 55,32 & 2,82 & $-0,55$ & $0.0000 * * *$ \\
\hline R33D & 26,71 & 1,90 & 26,87 & 2,01 & $-0,15$ & $0.0013^{* *}$ \\
\hline R55D & 39,89 & 2,57 & 40,06 & 2,66 & $-0,17$ & $0.0000 * * *$ \\
\hline R66D & 45,65 & 2,29 & 45,84 & 2,39 & $-0,19$ & $0.0000 * * *$ \\
\hline R77D & 52,55 & 2,46 & 53,00 & 2,53 & $-0,44$ & $0.0000 * * *$ \\
\hline
\end{tabular}

Nhân xét: Chiều rông cung răng hàm trên và dưới tữ năm 12 tuối đến 13 tuối ở nam và nữ đều tăng có ý nghĩa thống kề $(P<0,05)$. Tăng cao nhất là $R S T_{2}$ của nam (tăng $0,72 \mathrm{~mm}$ ) và tăng ít nhất là RTT của nam (tăng $0,12 \mathrm{~mm}$ )

\subsection{Sự tăng trưởng cung răng qua các năm từ 12 đến 14 tuổi}

Bảng 3.3. Tăng trướng chiều rộng cung răng giai-đoạn 12-14 tuổi

\begin{tabular}{|c|c|c|c|c|c|c|}
\hline $\begin{array}{l}\text { Đặc điểm nghiên } \\
\text { cứu }(\mathbf{m m})\end{array}$ & $\begin{array}{c}X \\
\text { năm } 12 \\
\end{array}$ & $\underset{\text { năm } 12}{\sigma}$ & $\begin{array}{c}X \\
\text { năm } 14\end{array}$ & $\begin{array}{c}\sigma \\
\text { năm } 14\end{array}$ & $\underset{(12-14)}{\Delta}$ & $\underset{(12-14)}{p}$ \\
\hline Nam: R33T & 36,20 & 1,81 & 36,62 & 1,81 & $-0,42$ & $0.0000 * * *$ \\
\hline R55T & 49,90 & 2,22 & 50,24 & 2,65 & $-0,34$ & $0.0000 * * *$ \\
\hline R66T & 54,73 & 2,21 & 55,40 & 2,64 & $-0,67$ & $0.0000 * * *$ \\
\hline R77 T & 59,06 & 2,71 & 60,40 & 2,81 & $-1,34$ & $0.0010 * *$ \\
\hline R33T & 35,07 & 1,80 & 35,52 & 1,81 & $-0,45$ & $0.0000 * * *$ \\
\hline R55T & 48,17 & 2,37 & 48,40 & 2,40 & $-0,23$ & $0.0000 * * *$ \\
\hline R66T & 53,00 & 2,23 & 53,42 & 2,45 & $-0,42$ & $0.0000 * * *$ \\
\hline R77T & 57,87 & 2,71 & 58,29 & 2,92 & $-0,42$ & $0.0000 * * *$ \\
\hline Nam: R33D & 27,82 & 1,69 & 27,85 & 1,98 & $-0,03$ & $-0.0003 * * *$ \\
\hline R55D & 41,78 & 2,32 & 41,79 & 2,52 & $-0,01$ & $0.0000 * * *$ \\
\hline R66D & 47,08 & 2,25 & 47,74 & 2,52 & $-0,66$ & $0.0000 * * *$ \\
\hline R77D & 54,56 & 2,81 & 55,32 & 2,82 & $-0,77$ & $0.0000 * * *$ \\
\hline R33D & 26,76 & 1,71 & 26,87 & 2,01 & $-0,11$ & $-0.0003 * * *$ \\
\hline R55D & 39,98 & 2,35 & 40,06 & 2,66 & $-0,08$ & $0.0000 * * *$ \\
\hline R66D & 45,53 & 2,21 & 45,84 & 2,39 & $-0,31$ & $0.0000 * * *$ \\
\hline R77D & 52,53 & 2,60 & 53,00 & 2,53 & $-0,47$ & $0.0000 * * *$ \\
\hline
\end{tabular}

Nhận xét: Chiều rông cung răng hàm trên, hàm dưới của nam và nữ từ năm 12 tuối đễn 14 tuối đều tăng, mức thay đổi có ý nghĩa thống kê $(p<0,05)$.

\section{BÀN LUÂN}

Trong số 226 trẻ em nghiên cứu có 107 đối tượng nam chiếm tỉ lệ 47,3 \% và 119 đối tượng nữ chiếm 52,7 \%. Đối tượng nam ít hơn nữ, tuy nhiên sự khác biệt này không có ý nghĩa thống kê $(p>0,05)$.Các số liệu trong nghiên cứ dọc được kết nối theo thời gian, qua đó không những đánh giá chính xác xu hướng cũng như mức độ tăng trưởng của toàn bộ mẫu nghiên cứu mà còn đánh giá cu thể trên từng cá thể ${ }^{8}$. Để đánh giá mức thay đổi tăng trưởng của các kích thước cung răng; chúng tôi tính mức chênh lệch tuyệt đối của các đặc điểm nghiên cứu $(\Delta)$ (bằng giá trị trung bình của đặc điểm nghiên cứu lần đo thứ nhất trừ đi giá trị trung bình lần đo thứ hai), p là mức ý nghĩa thống kê đánh giá sự tăng trưởng của các đặc điểm nghiên.

Mẫu tăng trưởng chiêu rộng cung răng hàm trên. Từ 12 đến 13 tuổi, hầu hết các kích thước chiều rộng cung răng $\mathrm{HT}$ của nam và nữ đều tăng, mức tăng có ý nghĩa thống kê $(p<0,05)$, tăng nhiều nhất là chiều rộng cung 
răng sau trên 2 của nam (R77T tăng 0,62 mm), tăng ít nhất là chiều rộng cung răng sau trên 2 của nữ (R77T tăng 0,03 mm), (bảng 3.1).

Giai đoạn 13 đến 14 tuổi(bảng 3.2) tất cả chiều rộng cung răng hàm trên của nam và của nữ đều tăng,sự thay đổi từ $0,12 \mathrm{~mm}$ đến 0,72 $\mathrm{mm}$, sự thay đổi này có ý nghĩa thống kê $(p<0,05)$. Chiều rộng hàm trên của nam tăng nhiêu hơn chiều rộng hàm trên của nữ, riêng RTT của nam (tăng $0,12 \mathrm{~mm}$ ) hàm trên tăng chậm hơn so với RTT của nữ hàm tăng 0,17 $\mathrm{mm}$ ). Tăng cao nhất là RST2 của nam (tăng 0,72 $\mathrm{mm})$. Tăng ít nhất là RTT ở nam $(0,12 \mathrm{~mm})$. như vậy ở giai đoạn này tốc độ tăng trưởng của cung răng mạnh mẽ hơn giai đoạn 12-13 tuổi.

Giai đoạn 12 đến 14 tuổi tất cả chiều rộng cung răng hàm trên của nam và của nữ đều tăng, sự thay đổi từ $0,23 \mathrm{~mm}$ đến $1,34 \mathrm{~mm}$, sự thay đổi này có ý nghĩa thống kê $(p<0,05)$. Chiêu rộng các cung răng sau trên của nam (R66T tăng0,67 mm, R77T tăng 1,34 mm) tăng nhiều hơn chiều rộng các cung răng sau trên của nữ (R66T tăng 0,42 mm, R77T cũng tăng 0,42 $\mathrm{mm}$ ), RTT của nam (tăng $0,42 \mathrm{~mm}$ ) hàm trên tăng chậm hơn so với RTT của nữ (tăng 0,45 $\mathrm{mm}$ ). Chiêu rộng giữa trên của nam (tăng 0,34 $\mathrm{mm}$ ) tăng mạnh hơn so với rộng giữa trên của nữ (tăng $0,23 \mathrm{~mm}$ ). (bảng 3.3).

So sánh kết quả tăng trưởng giai đoạn 12 đến 14 tuổi trong nghiên cứu của chúng tôi với kết quả nghiên cứu cùng giai đoạn 12 đến 14 tuổi của người Kinh ${ }^{9}$ chúng tôi thấy: Chiều rộng cung răng hàm trên trong NC của chúng tôi đều tăng $(0,23-1,34 \mathrm{~mm})$ điêu này giống kết quả nghiên cứu của Lê Đức Lánh ${ }^{7}$ trên trẻ người Kinh (Rộng cung răng trên tăng từ 0,2-1mm)nhưng có điểm khác nhau là RGT trẻ người kinh giảm $0,2 \mathrm{~mm}$ thì trẻ trong nghiêncứu của chúng tôi RGT tăng 0,34 mm. Đây cũng là đặc điểm khác nhau trong quá trình tăng trưởng cung răng của trẻ em người Kinh và trẻ em người Mường

Mẫu tăng trưởng chiêu rộng cung răng hàm dưới. Giai đoạn 12-13 tuổi chiêu rộng cung răng trước dưới và giữa dưới của nam và nữ giảm, sự thay đổi có ý nghĩa thống kê( $p<0,05)$. RTD, RGD của trẻ nam giảm mạnh hơn của trẻ nữ. Giảm mạnh hất là RTD của nam (R33D giảm $0,25 \mathrm{~mm})$. RSD1 và RSD2 ở nam và nữ đều tăng có ý nghĩa thống kê $(p<0,05)$ nhưng RSD1, RSD2 ở nam tăng mạnh hơn ở nữ. Tăng cao nhất là RSD1ở nam $(0,27 \mathrm{~mm})$. (bảng 3.1).

Giai đoạn 13 đến 14 tuổichiều rộng cung răng hàm dưới ở nam và nữ đều tăng, sự thay đổi từ $0,15 \mathrm{~mm}$ đến 0,55 mm. sự thay đổi đều có ý nghĩa thống kê $(p<0,05)$. Tốc độ thay đổi chiêu rộng của cung hàm dưới của nam mạnh hơn tốc độ thay đổi của cung răng hàm dưới của nữ.

Giai đoạn 12 đển 14 tuổi chiều rộng cung răng hàm dưới của nam và nữ đều tăng, sự thay đổi từ $0,01 \mathrm{~mm}$ đến $0,77 \mathrm{~mm}$. sự thay đổi đều có ý nghĩa thống kê $(p<0,05)$. RTD và RGD của nam (tăng 0,03 và $0,01 \mathrm{~mm}$ ) tăng chậm hơn so với ở nữ (tăng 0,11 và $0,08 \mathrm{~mm}$ ). Giống giai đoạn khác các chiều rộng cung răng sau dưới $\left(R S D_{1}, R S D_{2}\right)$ của nam đều tăng nhanh hơn so với của nữ.

So sánh kết quả tăng trưởng giai đoạn này trong nghiên cứu của chúng tôi với kết quả nghiên cứu cùng giai đoạn của người Kinh ${ }^{9}$ chúng tôi thây: Chiều rộng cung răng hàm dưới trong NC của chúng tôi đều tăng $(0,01-0,66 \mathrm{~mm})$ điêu này giống kết quả nghiên cứu của Lê Đức Lánh trên trẻ người Kinh cũng đều tăng (Rộng cung răng dưới tăng từ $0,1-0,6 \mathrm{~mm})^{7}$.

\section{KẾT LUÂ̂N}

Đây là nghiên cứu tăng trưởng đâuu tiên được thực hiện trên người mường. Kết quả đã xác định được xu hướng cũng như tốc độ tăng trưởng của cung răng của trẻ em người Mường giai đoạn 12 đến 14 tuổi.

\section{TÀI LIẸU THAM KHẢO}

1. Nguyễn Thị Thu Phương, Võ Trương Như Ngọc(2013), Tăng trưởng đầu mặt, Nhà xuất bản giáo dục Việt Nam, tr $(103,111)$

2. Sillman J. Dimensional changes of the dental arches: longitudinal study from birth to 25 years. Am J Orthod Dentofacial Orthop. 964;50:600-16.

3. Cassidy KM, Harris EF, Tolley EA, Keim RG. Genetic infuence on dental arch form in orthodontic patients. Angle Orthod. 1998;68:445-54.

4. Bishara SE, Jakobsen JR, Treder J, Nowak A. Arch width changes from 6 weeks to 45 years of age. Am J Orthod Dentofacial Orthop. 1997; 111:401-9.

5. Nojima K, McLaughlin RP, Isshiki Y, Sinclair PM. A comparative study of Caucasian and Japanese mandibular clinical arch forms. Angle Orthod. 2001;71:195-200.

6. Lindsten R, Ogaard B, Larsson E, Bjerklin K. Transverse dental and dental arch depth dimensions in the mixed dentition in a skeletal sample from the 14th to the 19th century and Norwegian children and Norwegian Sami children of today. Angle Orthod. 2002;72:439-48.

7. Lê Đức Lánh (2002), Đặc điểm hình thái đầu mắt và cung răng ở trè em từ 12 đên 15 tuổi tại Thành phố Hồ Chí Minh, Luận án tiến sỹ y học, Trường Đại học Y Dược Thành phố Hồ Chí Minh, tr.109-116

8. Phạm Cao Phong, Lê Gia Vinh, Võ Trương Như' Ngocc (2017), Sự thay đổi kích thước cung răng ở nhóm học sinh người Việt lứa tuổi 11-12, Tạp chí Y Học Việt Nam, tập 455 Số 2, Tr 1-4. 